\title{
La Ley sobre reforma de Haciendas municipales
}

\author{
por \\ SALVADOR ORTOLA NAVARRO \\ Protesor de Derecho administrativo en la Universidad de Madrid.
}

Sumario: I. Noticia.-II. El problema de las Haciendas locales.-III. Precedentes.-IV. La Ley de Bases de 1945. 1. Su necesidad. 2. Directrices de la reforma. 3. Su contenido. 4. Optimista acogida. 5. Críticas posteriores. 6. Critica de la Hacienda provincial.-V. La Ley de 9 de diciembre de 1953. 1. Causas y directrices de la nueva Ley. 2. Su contenido. 3. Comentarios que provocó su aparición.-VI. La nueva reforma. 1. Necesidad y urgencia de la reforma. 2. Directrices y motivos de la Ley: A) Supresión de la imposición municipal sobre el uso y el consumo. B) Cesión a los Municipios de determinadas contribuciones estatales y asuncion por el Estado de ciertas cargas municipales. C) Otras directrices. 3. Contenido de la reforma: el articulado de la Ley. 4. Disposiciones finales y disposición transitoria. 5. Conclusiones.

\section{NOTICIA}

El Boletín Oficial del Estado de 27 de diciembre de 1962 ha publicado (1) una Ley sobre reforma de las Haciendas municipales.

El presente artículo se encamina, simplemente, a dar noticia de su contenido y de la tendencia que la nueva Ley representa dentro de la cercana evolución de las Haciendas locales en España. No pretende, por lo tanto, un estudio exhaustivo de las cuestiones que su aplicación pueda promover, ni menos un juicio crítico acerca de la misma.

(1) Pág. 18285. 


\section{EL PROBLEMA DE LAS HACIENDAS LOCALES}

«Tópico es, y por ello realidad, hablar de la importancia de la materia, de la necesidad de resolver sus problemas, y de sentar las bases sólidas y suficientes de la economía financiera de Municipios y Provincias; dejémoslo por tanto apuntado que basta por ser muy conocida la retórica y datos con que de ordinario se adorna y fundamenta su demostración» (2).

El problema de las Haciendas locales es, en efecto, un tema manido, aunque nunca agotado. Los lectores de esta REvista conocen, además, sobradamente dicha problemática, y sería vana presunción intentar descubrirles ahora algún matiz inédito. La preocupación por el tema ha aflorado, por el contrario, en esta y otras publicaciones con la suficiente frecuencia para excusar hic et nunc mayor insistencia. Bastará, por ello, recordar los más próximos intentos de solución que se manifiestan en la legislación y doctrina españolas recientes, con el único fin de centrar exactamente la situación de la que la nueva Ley es a la vez fruto e intento remediador.

\section{PRECEDENTES}

La evolución legislativa que por el momento termina con la nueva Ley no es, desde luego, tan cercana que excuse toda remisión a antecedentes incluso seculares. Aun prescindiendo de la invocación a las Haciendas de la polis griega o de la urbs romana, e incluso de los Municipios medievales, o de nuestras ciudades de la época preconstitucional, es posible rastrear en nuestra Historia algunos importantes datos de la evolución de las Haciendas locales a partir, al menos, de la época constitucional. Pero, de un lado, no faltan en nuestra doctrina exposiciones de dicha evolución mucho más completas y autorizadas que la que en estos momentos cabría hacer (3) ; y de otro, la remisión a las

(2) Arana Arrieta: «Las Haciendas municipal y provincial en la Ley de Bases de Régimen local de 17 de julio de 1945», en esta Revista, núm. 22 , página 613.

(3) GASCON HERNÁNDEZ, José: «Hacienda estatal y Hacienda local», en esta Revista, núm. 73, pág. 3. 
mismas es suficiente para el limitado objeto que este trabajo se propone: exponer la problemática reciente, en nuestra Patria, de las Haciendas locales y las medidas que para su adecuada solución adopta la disposición legal comentada. Partiremos, pues, de época reciente: del momento en que se promulgó la Ley de Bases de Régimen local, de 17 de julio de 1945.

\section{LA LEY DE BASES DE 1945}

1. Dicha Ley representó «una reforma congruente con los nuevos supuestos de la vida pública» que el Movimiento Nacional había entronizado en nuestra Patria (4); una reorganización del régimen local acorde con ellos. Reorganización que, para ser fructífera, delía incidir necesariamente en la materia de Haciendas locales, ya que la esencia del nuevo Estado se reflejaba principalmente en «la necesidad de sustituir una visión abstracta de necesidades y de problemas por una visión realista que postule remedios concretos» (5), y si la Ley propugnaba la ampliación y efectividad de las competencias locales, hubiera resultado «inutil todo designio de reorganización de las Entidades locales si la finalidad político-administrativa de la reforma no estuviera respaldada por los medios económicos que constituyen clave indispensable del saneamiento de Municipios y Provincias»(6).

Se trataba, pues, no de reorganización teórica, sino de satisfacción de necesidades reales. $Y$ la realidad era que «el problema económico de las Provincias y de los Municipios pequeños no había sido satisfactoriamente resuelto con los Estatutos de 1924 y 1925, según lo demuestran... la lamentable situación de los servicios en la inmensa mayoría de las Provincias y pueblos» (7).

2. Las directrices de la nueva Ley se condensaban en los diez puntos que el Ministro de la Gobernación expuso ante las Cortes españolas:

— uniformidad de imposición;

(4, 5 y 6) Ruiz del Castiuro, Carlos: «Las bases de Régimen local. (Visión panorámica de la Ley de 17 de julio de 1945)», en esta REvista, núm. 22, página 567.

(7) SAURA PaCheCo: Principios y sistemas de Haciendas locales. Maard, 1949, pág. 13. 
- separación de las Haciendas municipal, provincial y estatal;

- exenciones tributarias a las Corporaciones locales;

- exención de la obligación de costear servicios de la Administración central;

- supresión de contribuciones de compleja aplicación;

- creación o cesión de nuevos recursos de carácter ordinario o extraordinario de sencilla y justa aplicación y de rápido ingreso en las arcas municipales y provinciales;

- reforma de otros para mejorarlos en sistema y rendimientos;

- habilitación de una fórmula para capacitar financieramente a los pequeños Municipios;

- limitación al justo y necesario mínimo de aumento en la presión tributaria;

- garantizar a las Corporaciones los resultados de la reforma en el período de transición.

3. En concreto, y aparte ciertas modificaciones de detalle menos importantes, la reforma puede resumirse así:

A) En lo municipal:

a) Cesión de impuestos.

Existían ya los de carruajes y caballerías de lujo y casinos y círculos de recreo. Se añaden determinados epígrafes de la tarifa $\mathrm{V}$ de la contribución de usos y consumos y el impuesto sobre vinos corrientes.

b) Participaciones en ingresos: se suprimen.

c) Recargos en impuestos:

Existían ya el 3 por 100 sobre el producto bruto de las explotaciones mineras y el que gravaba ciertos epígrafes de las tarifas $10^{\mathrm{a}}$ y $3 .^{\mathrm{a}}$ de utilidades.

Se duplican los recayentes sobre el consumo de gas y electricidad y la contribución industrial.

Se crean el del 44 por 100 sobre la contribución territorial rústica y el del 55 por 100 sobre la urbana, que integran la dotación del Fondo de Corporaciones locales.

d) Supresiones:

Los arbitrios de pesas y medidas, de inquilinato, el existente 
sobre el producto neto de las sociedades no gravadas por la contribución industrial o de comercio, el existente sobre productos de la tierra, y el repartimiento general de utilidades.

Como dijo SAINZ DE BuJANDA (8), la Ley «intenta dar una solución radical al problema de las Haciendas locales. No se trata ya de encontrar unos $u$ otros impuestos, de determinar el que mejor se adapte a la naturaleza de los servicios estatales o de los servicios municipales. Se trata de resolver el grave problema de las diferencias de estructura urbana y económica que entre los Municipios se ofrecen. $Y$ como solución, arbitra, por inspiración belga, el sistema del Fondo de Compensación de las Corporaciopes locales»... «Lo importante es que... el rendimiento de estos (nuevos) recargos se destinará en primer término a compensar totalmente a los respectivos Ayuntamientos de la supresión del repartimiento de utilidades, del arbitrio sobre los productos de la tierra y del de pesas y medidas, una vez aplicadas, sucesivamente, todas las demás exacciones establecidas en dicha Ley, a cuyo efecto se les fijarán cupos anuales que cubran la diferencia hasta la media de ingresos efectivos que obtuvieron en el último trienio, tomando esta medida como límite máximo. El remanente - un remanente que no ha llegado a existir-se distribuirá entre las Diputaciones provinciales en proporción a las recaudaciones obtenidas por estos recargos en las respectivas Provincias».

B) En la esfera provincial:

La reforma es aún más profunda. La supresión no sólo afectó a las participaciones, sino también a los recargos sobre arbitrios municipales, sin contar con que ya antes habían sido suprimidos impuestos y arbitrios importantísimos, que se sustituyen con los recargos siguientes:

- Un 24 por 100 sobre la contribución rústica y pecuaria.

- Un 41 por 100 sobre la industrial.

- Adicionales sobre una y otra.

- Los integrantes del llamado Fondo de Compensación pro-

(8) «La imposición municipal». Cátedra de Madrid (Curso Primero). Artes Gráficas Municipales. Madrid, 1954 (se trata de una conferencia publicada después, pero pronunciada antes, de la reforma de diciembre de 1953), página 235. 
vincial ( 5 por 100 sobre la contribución industrial y cinco y dos pesetas en los derechos de Aduanas sobre la importación de café y té).

4. La reforma, al parecer, colmaba las necesidades de las Corporaciones locales, y llegó a afirmarse que «con la ordenación de la materia de Haciendas locales en la nueva Ley se ha dado un grande y decisivo paso y se pone en manos de las Corporaciones locales un sistema económico que, bien organizado y administrado, les dará a todos recursos de numerario más que suficientes para desarrollar una gran labor en beneficio de los pueblos de las Provincias y de España» (9) ; y refiriéndose concretamente a la Hacienda provincial, que su problema «debe reputarse resuelto para un largo período de tiempo» (10).

5. Sin embargo, ya en el año 1953 hubo necesidad de reformar el sistema, duramente criticado antes de tal reforma. SAINZ dE BUJanda había señalado ya que el Fondo de Compensación había constituído un evidente fracaso. El remanente supuesto en la Ley de Bases no había llegado a existir «como efectivo sobrante, aunque sí como remanente en el sentido contable, ya que la vida de los Municipios hubiera necesitado para el cumplimiento de los servicios mínimos exigidos por la Ley municipal recursos superiores a los obtenidos de las exacciones que la base 22 deja en vigor, y de las cantidades obtenidas del Fondo de Corporaciones locales»... «Hay, pues, necesidad absoluta de acometer una nueva reforma de la Ley de Ordenación de las Haciendas locales: retoque al sistema, creación de figuras fiscales nuevas. Necesidad absoluta, por supuesto, de la supresión del Fondo de Compensación. El Fondo de Compensación, cuya idea esencial ha consistido, como dice su nombre, en compensar las deficiencias financieras de unos Municipios con una pretendida exuberancia de otros, a través de un organismo rígidamente centralizador y unitario, ha producido un retraso en las liquidaciones, debido a la existencia de un solo órgano y a la centralización de este organismo (en 1951 estaban pendientes de liquidación los ejercicios de 1948, 1949

(9) Arana Arrieta, Andrés: loc. cit., pág. 639.

(10) CAMACHo BaNos, Fernando: «Haciendas provinciales», en esta REvista, núm. 22, pág. 575. 
y 1950). La consecuencia es un tremendo y grave problema de tesorería para los Municipios, que se ven necesitados de acudir al crédito a corto plazo y a soluciones de tesorería incompatibles con la estabilidad de la Hacienda municipal. El segundo problema, quizá más grave, es que las fuentes de ingresos de que el Fondo de Corporaciones locales se nutre, a saber, los recargos de las contribuciones urbana y rústica, se canalizan a través del Fondo, sin discriminar el Municipio en que la riqueza imponible radica. No existe, pues, aliciente ni estímulo para el Municipio en que la riqueza imponible radica. Existe, por el contrario, una redistribución automática a través del Fondo de Compensación, sin una participación activa y directa del Municipio en la riqueza rústica y urbana que por vía de los recargos se incorpora a la Hacienda municipal» (11).

La conclusión no puede ser más desoladora:

«El problema de la Hacienda local es hoy más acuciante tal vez que en ninguna otra época de la historia moderna española... ¿Causas de esta situación? Ante todo, el carácter rígido de los impuestos municipales, carácter rígido que dimana, de una parte, de la negación de la soberanía fiscal municipal; de otra parte, de la carencia, a falta del principio de soberanía, de un recurso que permita adecuar los ingresos municipales a la coyuntura económica... Por otra parte, se señala también la extensión de la competencia municipal... Finalmente, la elevación de índices del nivel de vida... Por consiguiente, dificultad financiera actual; previsibilidad de dificultades financieras más graves para el futuro. La capacidad económica del Municipio es, además, absolutamente insuficiente para el cumplimiento de los servicios municipales indispensables» (12).

6. Tampoco en la esfera provincial tuvo fortuna la Ley de 1945. Según GASCóN HERNÁNDEZ, «Su nota más característica consistió en la congelación de los arbitrios sobre la riqueza radicante y los extraordinarios que venían disfrutando las Diputaciones provinciales. Esta solución, cuyos principios doctrinales pueden ser discutibles, tuvo como inconveniente el acentuar el sentido

(11) Loc. cit., págs. 236 y 238.

(12) Loc. cit., págs. 236 y 237. 
regresivo del presupuesto provincial y ser contraria al clamor unánime de las Diputaciones, que veían en este arbitrio el más adecuado para establecer sobre él un campo específico de imposición propia» (13).

\section{LA LEY DEЯ̆ DE DICIEMBRE DE 1953}

1. Estas y otras razones determinaron por fin la reforma de las Haciendas locales, que se llevó a cabo por Ley de 3 de diciembre de 1953. Una Comisión ministerial integrada por representantes de los Ministerios de Hacienda y Gobernación, que durante algunos meses actuó en el estudio de la reforma, sentó, en sus primeras reuniones, los siguientes principios:

1. El problema de las Haciendas locales es general, acusándose en todas las Corporaciones la necesidad de una revisión a fondo.

2. El sistema actual de ingresos es insuficiente, caracterizándose por su falta de elasticidad.

3. La Provincia y el Municipio pueden y deben tener un régimen económico propio, siempre subordinado al sistema impositivo general.

4.? La separación total de Haciendas estatal y locales es imposible.

5. Debe dotarse a las Corporaciones locales de recursos suficientemente elásticos, a fin de que el problema se resuelva con previsible permanencia.

6.- La solución sólo puede hallarse restableciendo algunos de los arbitrios suprimidos y con la utilización de recargos o participaciones en tributos nacionales.

2. Según estas directrices, se consumó la reforma, con las siguientes modificaciones, que resumimos siguiendo a GASCÓN HERNÁNDEZ (14) :

a) En lo municipal:

$\left.a^{3}\right)$ Supresión del Fondo de Corporaciones locales. Los recursos que lo dotaban-recargos-se convierten en arbitrios sobre

(13) Loc. cit., pág. 18.

(14) Loc. cit., pág. 20. 
rústica y urbana, en los que se señalan tipos de imposición máximos, elevándose solamente en la última el tope hasta la cuota del Tesoro.

b') Concesión a los Ayuntamientos de una participación del 10 por 100 del arbitrio sobre la riqueza provincial y de un recargo del 25 por 100 sobre el del producto neto, ambos recursos provinciales.

c) Nivelación presupuestaria para los Ayuntamientos deficitarios menores de 20.000 habitantes, a cargo de las Diputaciones provinciales.

d') Regulación de la prestación personal y de transportes para obras ordinarias.

b) En lo provincial:

$\left.a^{3}\right)$ Supresión del Fondo de Compensación provincial y de los recursos que lo dotaban.

b') Supresión de los recargos del 24 por 100 de rústica y del 5 por 100 de industrial, que se traspasa a los Ayuntamientos.

c) Concesión a las Diputaciones de tres arbitrios: el referido sobre el producto neto de sociedades y compañias, el de rodaje y el de la riqueza provincial. El último, fundamental en la reforma, comprensivo de distintos conceptos gravables.

c) Con carácter general:

$\left.a^{\prime}\right)$ Revisión de las bases y tarifas en la imposición privativa de las Corporaciones locales.

b') Mayor flexibilidad para el régimen de Carta económica y extensión, por primera vez, de este beneficio en favor de las Diputaciones provinciales.

3. No faltaron tampoco comentaristas a la nueva Ley. SAINZ DE BuJANDA se refirió a ella en el número 13 de la Revista de Administración Pública (15). FERNÁNDEZ DE LEÓN, en el número 114 del Boletin del Colegio Nacional de Secretarios, Interventores y Depasitarios de Administración Local (16), y Clavero ARÉVALo, en el siguiente número de la misma publicación (17),

(15) Pág. 237. «La reforma de las Haciendas locales».

(16) Pág. 265. «La nueva reforma de las Haciendas locales».

(17) Pág. 313. «Observaciones sobre algunos aspectos de la reforma de Jas Haciendas locales». 
dedicaron a la nueva Ley sendos artículos. En general, los augurios fueron felices, aunque no faltaron las reservas, referidas sobre todo al arbitrio sobre la riqueza provincial (debidas a su enorme discrecionalidad), al mecanismo de la nivelación presupuestaria y a la nueva ordenación de las Cartas económicas, sobre todo en lo referente a la posibilidad de que mediante ella se resucitasen exacciones suprimidas. Acaso la verdadera postura de los comentaristas citados pueda resumirse en una escéptica espera reflejada en estas o parecidas palabras, estampadas en sus comentarios: «En pocas ocasiones como en la presente puede tener tanta vigencia el tópico por el cual la bondad de la eficacia de las leyes depende más de quienes las aplican que de quienes las hacen» (18).

\section{LA NUEVA REFORMA}

1. Un Proyecto de Ley redactado por el Gobierno con sorprendente celeridad y tramitado con igual urgencia se ha convertido, definitivamente, en Ley (19).

$\mathrm{Su}$ preámbulo comienza aludiendo a la necesidad de una radical reforma de las Haciendas municipales, que afirma haber retrasado la efectividad del Plan de Estabilización y la consiguiente coyuntura económica del país.

2. Las directrices y motivos de la reforma son las siguientes:

A) SuPREsión DE LA IMPOSICIÓN MUNICIPAL SOBRE EL USO Y EL CONSUMO.

El preámbulo destaca lo radical de la supresión y su alcance económico (20), y afirma que «las exacciones que desaparecen unían a su anacronismo el gravitar de manera muy sensible sobre sectores económicamente débiles, producían auténticas barreras en el interior del país, provocaban para el contribuyente una desigualdad geográfica injusta e inconveniente $\mathrm{y}$, a mayor abundamiento, contribuian de manera muy primordial a producir o

(18) Clavero Arévalo, M. F.: loc. cit., pág. 346.

(19) Con importantes modificaciones, pese a todo.

(20) «Una desgravación equivalente a 3.740 .000 .000 de pesetas, que representa algo más de la cuarta parte del importe total de los presupuestos munlcipales ordinarios». 
enmascarar injustificadas elevaciones de precios, incluso en artículos de primera necesidad».

B) Cesión a los Municipios de determinadas contribucioNES ESTATALES Y ASUNCIÓN POR El Estado DE CIERTAS CARGaS MUNICIPALES.

Como compensación a la pérdida de aquellos recursos, el Estado asume el abono de haberes al personal sanitario y cede a ios Municipios gran parte de los ingresos proporcionados por la contribución territorial urbana y la cuota de licencia fiscal; del preámbulo se desprende que «así se adscriben al levantamiento de las cargas locales dos fuentes de riqueza marcadamente influídas por la actividad municipal y que por su alcance permitirán a estas Corporaciones contar con ingresos no sólo de cuantía equivalente a los que pierden, sino incluso en un futuro próximo muy superiores a los actuales.

»Ahora bien, la cesión de estas contribuciones ha de hacerse con flexibilidad, para evitar un repartimiento notoriamente desigual de los nuevos ingresos entre los distintos Municipios, ya que si esto no se asegurase cabría la posibilidad de que siendo acertada la reforma en sus líneas generales se produjeran injusticias concretas que la malograsen. De ahí el juego del Fondo Nacional que se establece como corrector de esas injusticias mediante la equitativa distribución a través de los recursos que no resulten directamente cedidos a cada Ayuntamiento».

El Estado promete además que en ningún caso resultará perjudicado, ni siquiera en su fase transitoria, ningún Ayuntamiento, y compromete en ello, si es necesario, su futuro sacrificio.

La asunción por el Estado del pago de haberes del personal sanitario («vieja aspiración-dice el preámbulo-tanto de este personal como de los Ayuntamientos hasta ahora obligados al pago») deja a cargo de los Ayuntamientos las diferencias superiores a los mínimos legales, que se respetan como derecho personal y «a extinguir».

C) Otras directrices.

Otras finalidades de la Ley son la simplificación recaudatoria, la modificación de las normas que regulan las contribuciones espe- 
ciales (se autoriza al Gobierno para acomodarlas-dice el preámbulo-a las dictadas por la Ley especial de Barcelona) y la supresión del recurso especial de nivelación de presupuestos («para poner término a un sistema que frenaba estímulos»). Sus fondos pasan a incrementar los créditos para la cooperación provincial a los servicios municipales.

«Con todo ello-termina el preámbulo-se inicia una reestructuración de las Haciendas municipales y al mismo tiempo se abre camino para que una eficaz política de contención de precios pueda coronar en la esfera nacional el paso importantísimo que ahora se da en la local, donde se eliminan tradicionales obstáculos que contribuían a encarecimientos nada despreciables».

3. Con arreglo a tales criterios, se suprimen los siguientes recursos (21):

Primero.-La tasa por vigilancia y reconocimiento sanitario de reses, carnes, pescados, leche y otros mantenimientos destinados al abasto público a que se refiere el número 5 del artículo 440 .

Segundo.--El arbitrio con fin no fiscal que grava el precio de las consumiciones en cafés, bares, tabernas, restaurantes, hoteles y otros establecimientos similares, regulado por el artículo 476.

Tercero.-La antigua tarifa quinta de la contribución de usos y consumos, cedida por el Estado a los Municipios, a que aluden los artículos 478 a 483, ambos inclusive, excepto los epígrafes 23 y 27, en su actual redacción, y el número 19, con el siguiente texto: Consumiciones en hoteles y restaurantes de lujo, en servicio a la carta o minutas especiales, siempre que, tratándose de hoteles, no formen parte de la pensión completa. El gravamen girará sobre la cuantía, incluso el recargo del servicio. Si no existiese minuta especial, se considerarán en este gravamen las superiores a 30 pesetas..., 10 por 100 .

Si en la consumición se incluyeran partidas correspondientes a aperitivos, cafés, licores y demás propias de bares, éstas tributarán al 20 por 100.

Cuarto.-El impuesto sobre el vino y la sidra, también cedido a los Ayuntamientos, que se rige por el artículo 484 .

(21) Artículo 1., uno. 
Quinto.-El recargo sobre el impuesto que grava el consumo de gas y electricidad, con arreglo al artículo 489.

Sexto.-Los arbitrios sobre el consumo de bebidas espirituosas y alcoholes, carnes, volatería y caza menor y pescados y mariscos finos, comprendidos en los artículos 525 al 554, ambos inclusive.

Séptimo.-Los impuestos que con carácter especial, tradicional o extraordinario tengan establecidos los Municipios y graven el consumo, al amparo del artículo 752 de la Ley de Régimen local.

La supresión es total; aun cuando el Municipio deba seguir prestando los servicios antes gravados con tales recursos, no podrá «exigir percepción alguna por su prestación, cualquiera que sea su forma» (22), ni «gravámenes ni arbitrios por tránsito a través de poblaciones por cualquiera de los artículos de consumo que quedan desgravados en el apartado anterior» (23), ni «establecer ni percibir, salvo autorización por Ley, ninguna exacción ordinaria ni extraordinaria que tenga por objeto los mismos hechos imponibles que los tributos que se suprimen» (24).

Para compensar la pérdida de estos recursos, y aparte la asunción por el Estado de la obligación del pago de los haberes del personal sanitario (25), se cede a los Ayuntamientos el 90 por 100 de la recaudación líquida por cuota del Tesoro, de la contribución territorial, riqueza urbana (incluído el recargo actual del 40 por 100 sobre dicha cuota y el procedente de las zonas de ensanche) y el 90 por 100 de la recaudación líquida por cuota de licencia fiscal del impuesto industrial (porcentajes que se revisarán quinquenalmente) (26).

Dichos recursos se distribuirán de la siguiente forma (27):

a) Directamente a cada Ayuntamiento, en concepto de entrega a cuenta de la liquidación definitiva y con el carácter de recursos mínimos, una suma equivalente a las cantidades recau-

\footnotetext{
(22) Articulo 1. $0^{\circ}$, tres.

(23) Artículo 1.9, dos.

(24) Artículo 4.

(25) Artículo $7 .^{\circ}$

(26) Artículo 8.9

(27) Artículo 9.9
} 
dadas durante el ejercicio de 1961 por las exacciones suprimidas por esta Ley, más un 15 por 100, incrementada, en su caso, con una cantidad igual al importe del recurso nivelador fijado para 1963 por resolución firme anterior a la entrada en vigor de esta Ley, y en su defecto, al señalado para 1962, siempre que el respectivo Ayuntamiento lo hubiera solicitado también para 1963.

Las entregas se efectuarán por dozavas partes en la segunda quincena de cada mes, a los Ayuntamientos de más de 2.000 habitantes, y por cuartas partes, en la segunda quincena del segundo mes de cada trimestre, a los Ayuntamientos restantes.

b) Al Fondo Nacional de Haciendas municipales que se crea, se asignará el remanente, si lo hubiere.

El Fondo Nacional de Haciendas municipales estará regido por una Comisión presidida por el Subsecretario de Hacienda e integrada por los Directores generales de Administración Local y de Régimen Fiscal de Corporaciones, y por dos representantes de los Municipios, uno de Ayuntamiento que sea capital de Provincia y otro de los restantes, designados ambos por el Ministerio de la Gobernación.

La Comisión deberá proceder anualmente a distribuir los créditos presupuestos a que se refiere el subconcepto $b$ ) del artículo 8., entre los Ayuntamientos, de la siguiente forma: el 50 por 100 , en proporción al número de habitantes de derecho, y el 50 por 100 restante, en proporción a los líquidos imponibles por la contribución territorial de la riqueza urbana de cada $\mathrm{Mu}$ nicipio.

Estas son las principales innovaciones de la Ley, sin perjuicio de las ya citadas al examinar sus directrices-modificación de las contribuciones especiales (28) y supresión del recurso especial de nivelación de presupuestos (29) - y de alguna otra, como la nueva regulación de las exenciones fiscales en favor de los Ayuntamientos, para actualizar las cuales se autoriza al Gobierno: la exención total del impuesto de derechos reales en favor de las subvenciones de fondos públicos concedidas a las Corporaciones locales, o la autorización concedida también al Gobierno

(28) Articulo 5.ค

(29) Artículo 6.9 
para regular el sistema de exacciones y bonificaciones en materia de exacciones municipales (30).

4. La Ley (31) termina con siete disposiciones finales y una transitoria, referente a presupuestos del año 1963, de todos los Ayuntamientos afectados.

La primera de aquéllas determina los artículos de la vigente Ley de Régimen local que quedan derogados (32); las segunda a cuarta se refieren a la vigencia espacial de la norma, así como la sexta, que se ocupa concretamente de la situación que frente a ella corresponde a la reciente Ley especial de Barcelona (33); la quinta establece como fecha de entrada en vigor de la disposi-

(30) Artículo 10.

(31) Consta de diez artículos, todos ellos ya aludidos.

(32) Primera. Quedan derogados el número 5 del artículo 440, el artículo 476, el apartado i) del artículo 477, el artículo 484, los artículos 489 y 525 a 554, ambos inclusive, y los artículos 573 a 577, ambos inclusive, de la Ley de Régimen local, texto articulado de 24 de junio de 1955, y demás disposiciones en cuanto se opongan a lo establecido en esta Ley. Se derogan asimismo los artículos 478 a 483 , ambos inclusive, de la Ley de Régimen local antes mencionada, salvo las normas de dichos preceptos que sean aplicables a la recaudación de los epigrafes 23 y 27 de la tarifa quinta de la contribución de usos y consumos y del 19 con arreglo al texto incorporado al artículo 1.9, apartado 1, número 3, de esta Ley de Reforma de Haciendas municipales y el artículo 572 en cuanto grava el consumo.

Es evidente que no son sólo estos artículos los que resultan afectados en la hasta ahora vigente Ley de Régimen local. A título de ejemplo, es indudable que el artículo $4 .^{\circ}$ de la Ley de Reforma añade una prohibición esencial al artículo 241 de la Ley actual, en cuanto impide a los Ayuntamientos modificar el régimen tributario legal, restableciendo en sus Cartas económicas los recursos en la nueva Ley suprimidos.

(33) Segunda. La presente Ley no será de aplicación en Alava y Navarra, que continuarán ateniéndose a su régimen especial.

Tercera. El Gobierno dictará las medidas especiales que sean precisas para la aplicación de esta Ley en las Provincias del Archipiélago canario, asi como en Ceuta y Melilla, atendidas las peculiaridades de su régimen local.

Cuarta. Las normas del artículo $7 .^{\circ}$ se aplicarán a las ciudades de Ceuta y Melilla.

Quinta. Los preceptos de esta Ley entrarán en vigor el 1 de enero de 1963.

Sexta. Se autoriza al Gobierno, a propuesta de los Ministros de Hacienda y de la Gobernación, para revisar el régimen especial de Barcelona aprobado con carácter de Ley especial, texto de 23 de mayo de 1960, para acomodarlo a la nueva ordenación de las Haciendas locales. A partir de 1 de enero de 1963 quedarán suprimidas las exacciones comprendidas en el articulo 1.: de la presente Ley. 
ción el día 1 de enero de 1963, y la séptima adopta determinadas medidas presupuestarias, de ámbito estatal, para posibilitar la efectividad de los mandatos legales.

5. Queda aîrmado más arriba (34) el simple propósito que nos animaba al pergeñar este comentario y la ausencia de todo intento de profundo estudio o crítica. Sin embargo, sería sobrada comodidad eludir absolutamente cualquier consideración sobre la trascendencia, oportunidad y acierto de la nueva ordenación.

Ante todo, parece sorprendente el hecho de que nos hallemos ante una Ley que modifica intensamente el régimen de las Haciendas municipales y para nada se ocupa del problema de las provinciales. $\mathrm{Y}$ tanto más cuanto ha sido precisamente el arbitrio sobre la riqueza provincial el tributo que la doctrina ha considerado, quizá, el más peligroso para las metas de justicia distributiva, abaratamiento de precios y progresividad impositiva que la nueva Ley persigue (35). Aun pensando que nos hallamos simplemente ante una primera etapa de la reforma de Haciendas locales, a la que hubiera de seguir inmediatamente la de las $\mathrm{Ha}$ ciendas provinciales, parece necesario preguntarse si no hubiera sido preferible su realización conjunta, si es posible acometer parcialmente-en el más exacto sentido de la palabra-un problema tan arduo y plurifacético como el que nos ocupa.

Hecha esta observación, la reforma ofrece indudablemente sensibles ventajas para el contribuyente, las cuales explican la buena acogida que entre el público español ha tenido la Ley, debida principalmente a la supresión de los arbitrios sobre el consumo, supresión que se supone ha de abaratar el precio de los productos desgravados (36). Desde el punto de vista de los Mu-

Esta última disposición supone una regresión-aun cuando sea por razones justificadas-a la uniformidad de régimen de los Municipios españoles; uniformidad que se acentúa si se advierte que en virtud del artículo $5 .^{\circ}$ de la nueva Ley, se opera en igual dirección, aun cuando en sentido contrario, es decir, acercando el régimen general español al creado para Barcelona por su Ley especial.

(34) Véase pág. 817.

(35) Aparte de Clavero Arévalo, loc. cit., y de Sainz de Bujanda ( $\ll$ La reforma de las Haciendas localess, ya citada), se ha ocupado recientemente del tema Jaime Garcí ANoveros ( $₫ \mathrm{El}$ arbitrio sobre la riqueza provincial») en Problemas politicos de la vida local, tomo II, I. E. P., Madrid, 1962.

(36) Este parece haber sldo en realidad el motivo decisivo de la reforma. Constituye el núcleo fundamental de la exposición de motivos y, de otro 
nicipios, la acogida en todos los casos no ha sido tan optimista. Muchos municipalistas han visto en la Ley un golpe asestado a la suspirada autonomia municipal, $y$ ello ha bastado para prevenirles en su contra. Sin pretender negarlo, creemos que no es tampoco en este terreno en donde ha de plantearse la cuestión, sino en el puramente hacendístico (37). Procede, ante todo, preguntarse si la Ley aumenta efectivamente, y en qué cuantía, los recursos municipales y, aun por encima de ello, si la mejora alcanzada es suficiente para el efectivo desenvolvimiento de la vida municipal o, en todo caso, representa la mejor de las soluciones hic et nunc posibles.

En este orden, la respuesta no es fácil, entre otras cosas porque no lo es hallar una respuesta unívoca a la cuestión «óptima

lado, de las declaraciones informativas de los hombres de la reforma. Véanse, por ejemplo, las siguientes, publicadas en El Consultor de los Ayuntamientos (número 34, pág. 1482), del Ilmo. Sr. Director general de Administración Local, sobre la futura Ley:

«Todo el Proyecto de Ley que en breve examinarán las Cortes Españolas gira alrededor de innovaciones tan deseadas y tan revolucionarias, valga la redundancia, como es la supresión de los arbitrios municipales conocidos con el nombre de «Usos y Consumos». Ello era un antiguo desideratum perfectamente natural en la época actual, lejos ya de las antiguas Haciendas medievales. La supresión de los citados arbitrios era, por tanto, una exigencia insoslayable, si se quiere estar en línea con la economía mundial y si se pretende seriamente acercarnos al cada vez más pujante Mercado Común; la otra alternativa hubiera sido continuar en un anquilosamiento que, en breve tiempo, habría dejado a España al nivel de las que hoy pasan por civilizaciones primitivas.

»Por otra parte, no puede juzgarse con auténtica realidad una reforma como la presente, limitándonos al examen de la misma, fuera de la realidad total en la que está incardinada. Y la reforma de las Haciendas municipales, sucesora inmediata de la política de estabilización de nuestro Gobierno, ha precedido, aunque sólo sea por breves días, a Decreto tan importante para la economía española como es el recentísimo de 23 de noviembre, referente a la puesta en marcha definitiva del Plan de Desarrollo Económico. La reforma que comentamos era absolutamente necesaria, pues de no haberla realizado en tal momento, las Haciendas locales se hubieran visto rebasadas y superadas por el Plan de Desarrollo Económico, al cual hubieran tenido que adaptarse de todas maneras, pero entonces $a$ fortiori y no al paso que su propia esencia reclama».

Las restantes medidas que la Ley adopta son con carácter compensador o complementario, cuando no ocasional.

(37) Aun cuando sea de lamentar, y en cualquier grado que ello deba hacerse, es lo cierto que el de la autonomia local parece un pleito perdido, aun antes de la Ley que comentamos. 
regulación de la Hacienda local», aun desechado el fácil arbitrismo (38). La reforma es bienintencionada, aunque pueda discutirse que se trate de una solución nueva. Importa, a nuestro modo de ver, no sólo el origen de los fondos (39), sino su cuantía y la forma de su disponibilidad, y en este aspecto no parece aún posible proclamar vencidos los graves defectos de la falta de elasticidad y la carencia de estímulo que en cuanto a ingresos se achacaron al régimen anterior $(40)$.

De todas formas, resulta forzoso reconocer de nuevo la eficaz intención que anima la reforma y sus positivas ventajas, que si no llegan, en nuestra opinión, a convertirla en solución cercana a la ideal, resuelven dificultades existentes y pueden en efecto, al menos en lo que se refiere a algunos Municipios, representar para éstos un positivo incremento de sus haciendas.

La Ley significa, pues, un paso más hacia el mejoramiento de las Haciendas municipales, aunque no un definitivo logro.

(38) Aparte las consideraciones que sienta en este orden Gascon HeRNáNDEZ en el trabajo ya citado y SAINZ DE BUJANDA en «La imposición municipal», también citada ya, y por no referirnos sino a otro de los autores que recientemente se han ocupado del tema, puede ser consultado Galvaf Escutia: «El poder económico municipal» (Problemas politicos de la vida local, tomo II, I. E. P., Madrid, 1962, págs. 99-117), especialmente las tres últimas páginas del trabajo, que se ocupan de la insuficiencia del poder impositivo municipal.

Por cierto que, respecto del problema de la autonomia financiera, pueden recordarse las palabras que cierran dicho trabajo como sintesis de la opinión del autor: «Sólo cuando los órganos rectores municipales demuestren con sus actos la correcta aplicación y destino de los ingresos y exacciones locales para atender los gastos necesarios y útiles, administrándolos como buen padre de familia, podrá existir legitimamente el poder económico municipal».

Este parece ser el inevitable criterio práctico de heteronomia imperante en las legislaciones, y concretamente en la nuestra.

(39) En este aspecto, la Ley se acerca mucho a la solución propuesta por autores como GalvaN Escutia y SAINZ DE BUJANDA, incluso en algan matiz formal.

(40) No parecen totalmente infundados los temores, de que se hace eco el interlocutor del Ilmo. Sr. Director general de Administración Local en la entrevista ya aludida, de que el ruevo Fondo Nacional actúe en la práctica de forma similar a como lo hicieron el antiguo Fondo de Compensaciones o el posterior de nivelación presupuestaria, cuyas deficiencias son sobradamente conocidas, por lo que cabe esperar, al menos, una importante mitigación de las mismas. 